histologically before that diagnosis was submitted.

Mr. EwING: We had a good photograph of a woman in this hospital who had a very large parotid tumour below the angle of the mandible, and who was treated by radiotherapy alone.

Prof. AIrd: The Swedes are very cautious in their classification of these mixed tumours and they describe three varieties; the benign variety, the potentially malignant variety and an intermediate variety (which includes 40 per cent. of all tumours); the criteria they adopt for malignancy are:-Cell type, nuclear type, extension beyond capsule, invasion of blood vessels and papillary formation. This particular tumour would be considered to have a good prognosis. These criteria they describe refer only to local malignancy as one would use the word in connection with a basal cell tumour, and I do not remember them describing a case of metastasis.

Mr. EwING: In Sweden I saw a Lapland woman with a mixed parotid tumour she had had for 20 years. It had grown to the size of her head and was tucked in a shawl, but of course we endeavour not to have people in this country walking around with tumours of this kind.

Prof. AIRD: If, as the Swedes did, you count up the years, taking the average number of years of duration of a benign salivary tumour, and of a malignant salivary tumour, they are almost identical. Benign are present for about nine years before they report for treatment, and malignant about seven years.

Mr. Peter Martin: It has been my feeling that these tumours must be treated seriously. I would be inclined to think that if it were feasible the parotid gland should be removed. I would certainly always try to remove some gland tissue with the capsule, and I have one very severe recurrence which was absolutely inoperable.

PROF. AIRD: When recurrence does happen the histological appearance is always very similar to the original tumour. However, the rapidity of tumour growth is always very much greater on each successive recurrence than it was in the original tumour. The reason seems to be that the original operation does interfere with the capsular arrangement of the tumour and makes local spread of any remnants easier. I am entirely satisfied that the treatment of these is by local excision and subsequent irradiation. I met the Edinburgh radiotherapist, Dr. McWhirter the other day. We treated a few tumours by this method about six years ago by inserting radium needles to get a very high local concentration of radiation and in none of these cases has there been recurrence. Miss Constance Wood here uses irradiation after the manner of Finsey, using glancing fields across the cheek after we have done the excision.

\title{
Malignant Melanoma of Leg
}

Case History (Mr. J. J. Shipman)

The patient, a woman aged 30 years, was admitted to this hospital with a pigmented tumour of the skin of the left leg. On questioning it appeared that a mole had been present there as long as she could remember. Two years ago this spot had begun to increase in size. She noticed in addition to it becoming larger in diameter it was also becoming raised above the surface of the adjacent skin. Four months prior to admission the growth was about the size of the nail of the little finger, and about this time she broke the surface of it with a finger nail; it then discharged some mauve-brown jelly, followed by a discharge of watery material and blood. Following this event the wound healed, but since then she had noticed an acceleration in the rate of growth. She had not noticed any lumps appearing elsewhere and she has no cough.

On examination of the left leg the tumour was seen just above the middle of the medial border of the left tibia (Fig. I). The surface of the tumour was raised $\mathrm{I} \mathrm{cm}$. above the surrounding skin. The re was a shallow constricting ring around the base of the growth suggesting pedunculation. The surface of the tumour was covered by silvery flakes divided by clefts into segments, and was mauve in colour. The tumour felt as though it contained fluid surrounding a solid core. The growth was limited to the skin and could be moved on the subcutaneous tissues. A small soft gland was found in the left groin and a radiograph of the chest was normal. There were no abnormal physical signs in the abdomen.

Biopsy excision was decided upon by Mr. Franklin, and this was performed by Mr. Chris. The whole tumour was removed, together with an area of normal skin and an area of deep fascia. Post-operative progress from this operation was satisfactory and it was followed by a block dissection of the glands of the groin two weeks later. The excision of the block of tissues was performed through a $\mathrm{T}$-shaped incision and, in addition to the main mass, a gland was removed from the femoral 


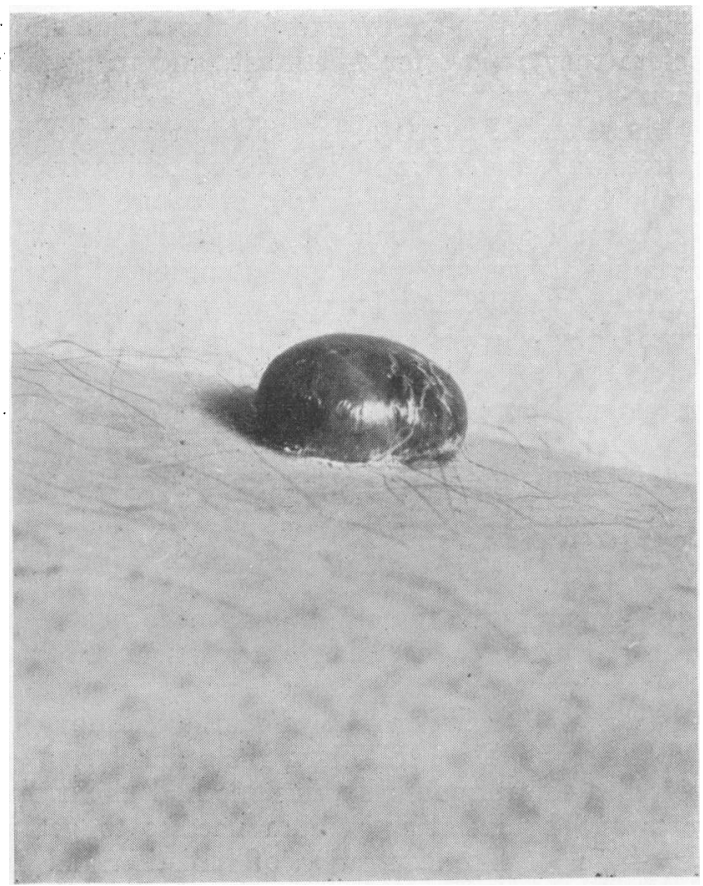

Fig. I

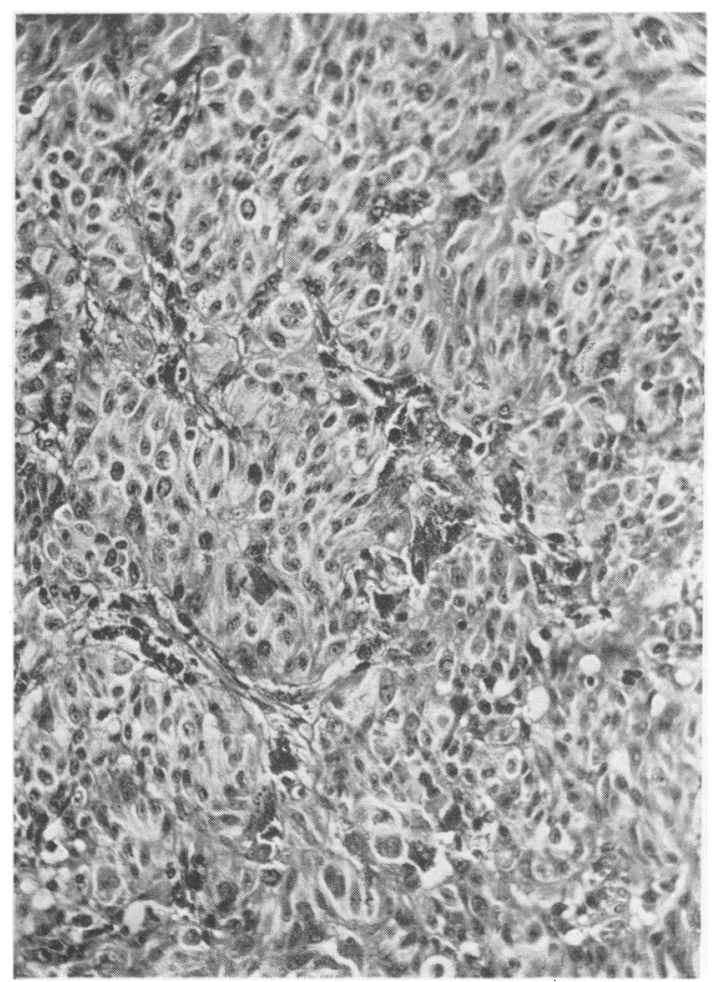

Fig. 3

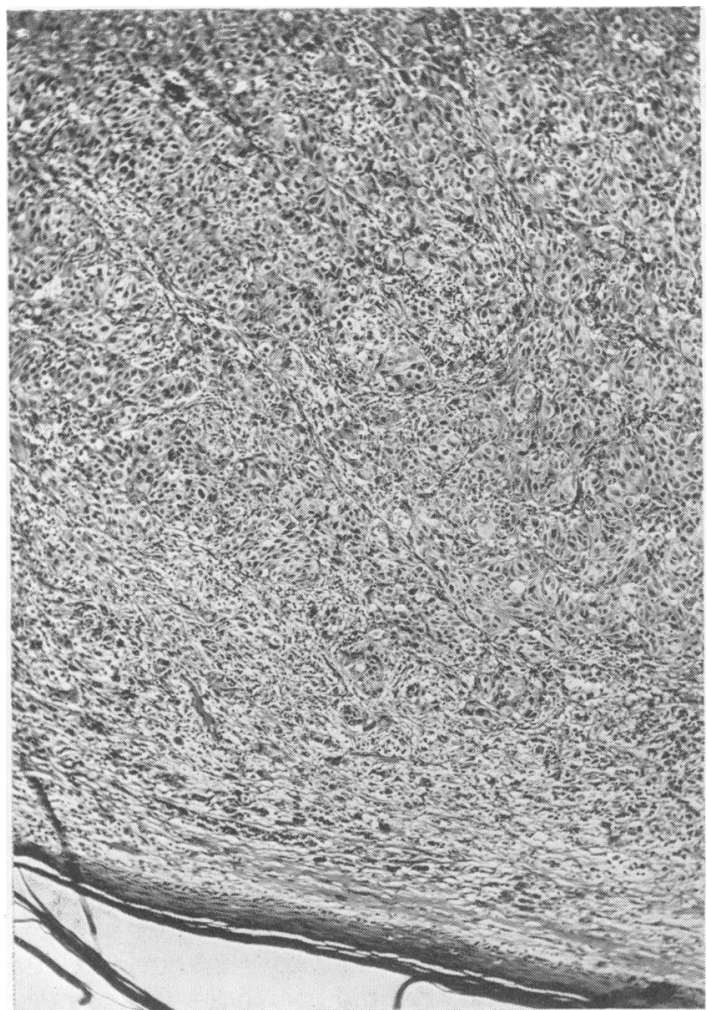

Fig. 2

canal and another fragment was removed from the deeper aspects of the femoral triangle. The progress following this operation has been satisfactory.

\section{Pathology (Dr. Mason)}

The specimen, as can be seen, consisted of a sessile rounded tumour $15 \mathrm{~mm}$. in diameter and Io $\mathrm{mm}$. in height. At the base it was attached to an elliptical piece of skin, the diameter of the base being $10 \mathrm{~mm}$. Subcutaneous tissue to a depth of $20 \mathrm{~mm}$. was included in the specimen. The colour of the tumour on section is bluish-brown.

Histologically the tumour is seen to consist of clusters of cells, with the clusters separated by collagen fibres (Figs. 2 and 3). For the most part the cells are large, polygonal or oval with palestaining nuclei and abundant cytoplasm. In other parts, however, the cells can be seen to be more spindle shaped and arranged in a fascicular fashion. Pigment-bearing cells are seen in large numbers in the tissues and while the cytology of the tumour masses is quite typical it is essential first to prove the nature of the pigment.

The next slide, which is stained specifically for 
melanin, shows conclusively that the pigment present is, in fact, melanin. It will be seen, though, that the majority of the tumour cells are free from pigment; only certain nests of cells, particularly those near the base, show the presence of very fine granules of melanin. The majority of the pigment is present in very coarse form in cells which are concentrated in the connective tissue and which are melanophores. I have stained a section for the presence of free iron which, as would be expected, is negative, and another preparation shows the reticulin pattern of a naevus cell tumour.

Returning to the original section, the epidermis over the tumour is flattened and thinned. The tumour itself is wholly intradermal and there is no evidence of junctional change. The tumour cells themselves are very large and pale, and mitotic figures are fairly numerous.

Turning to the base of the tumour the lower margin is rather clean cut and is situated only slightly below the level of the surrounding epidermis. Examination under higher magnification shows, however, that small groups of tumour cells can be seen below the general level of the main tumour and these give a definite impression of early invasion. Associated with the base of the tumour are groups of lymphocytes indicating a mild inflammatory reaction. Miecher has stated that the presence of an inflammatory reaction is an indication of malignancy. I have, however, no experience of this sign and only mention it as a quotation.

The section on the last slide is a specimen of several lymph glands dissected from the inguinal block dissection. It is free from tumour as were all the other glands examined.

To sum up, therefore, the constituent cells of this naevus cell tumour have the characteristics of malignancy; mitotic figures are present; there is evidence of apparent infiltration and, for what it is worth, there is a lymphocytic reaction at the base of the tumour. Despite the fact that there is no junction activity and no metastasis one must, on histological grounds, regard this as a malignant melanoma.

\section{Discussion}

DR. Mason: We have here a melanoma which shows mitotic figures and infiltration, and there is no doubt that this is a malignant melanoma.

Prof. Aird: Mr. Shipman, we are wondering what led to the diagnosis of malignant melanoma.

Mr. Shipman: Just the rate of growth.

Prof. AIRD: Dr. Mason says malignant melanoma, but do you really reserve the term ' melanoma' for malignant pigmented tumours?

Dr. Mason: I think so.

DR. LENNOX: There is no pathologically satis- factory term. Naevus really means birthmark; you cannot call it a naevus yet tumour is the next best thing, and the only characteristic thing about it is that it is a benign tumour of melanoblasts and therefore its term should be a melanoma.

Mr. EwInG: Could Dr. Lennox give us a definition of melanoma?

Dr. LenNox: A tumour of melanoblasts.

Dr. Powell: What would you call a benign melanoma which contained pigment?

DR. Lennox: Perhaps the term 'melanoma' should be 'melanoblastoma.'

PROF. AIRD: I was engaged in discussion the other day about how often the malignant melanomas we see arise in previously present benign, pigmented tumours, and it is my opinion that it is not the commonest way they present. One sees it, but it is so much more common either to get a new pigmented tumour or a new tumour of independent character which pathologists report as a malignant pigmented tumour.

Mr. EwING: In the Leeds analysis about $5^{\circ}$ per cent. gave a history of some pre-existing lesion. My impression is that it is rather an exception to have a pre-existing lesion. What is the definition of a mole, Mr. Shipman?

Mr. Shipman: The patient described it as a mole. She has other spots on her body, and most of us have similar pigmented spots. I do not know the definition of a mole.

Prof. AIRD: I hope you do not think that 'pigmented spot' is likely to be any more acceptable to Dr. Lennox than pigmented mole!

DR. LenNox: I think pigmented mole is the description of any coloured spot of long duration and the term naevus is merely an abnormally . . .

PROF. AIRD: You mean abnormally coloured spot?

DR. LenNox: Yes. Would you not agree that naevus is used equally for vascular tumours?

Prof. AIRD: There is not much danger of dissemination of a pigmented tumour of the leg. Lymphatic spread is common and frequent but they do not behave in a metastatic way as orbital melanomas.

Dr. Harrison: May I quote Wright from Leeds in the F. Path. and Bact., I949, 6r, 507, who studied a 23 years' collection of pigmented tumours, all malignant melanomas of the skin; 28 per cent. survived five years and $12 \frac{1}{2}$ per cent. survived ten years, which is not bad. Of malignant eye cases 62 per cent. survived five years and 39 per cent. survived ten years. A very interesting little point was that of tumours recorded by the pathologists as doubtful, none recurred and none had metastases. If such a tumour is doubtful it is probably all right. A very interesting last point they made was that if a patient with a skin tumour 
survives five years and is still free from all signs of recurrence it is probably all right, but for an eye tumour the figure is ten years before the patient is all right. Really late recurrences are unusual in skin but do occur in eye cases.

Mr. EwING: Malignant melanomas do not occur in children.

Dr. Harrison: The dividing line is puberty. 'Ihere is actually one report in the literature within the last month of a metastasizing malignant melanoma in a child.

Prof. AIRD: I think I am right in saying that there have been two congenital malignant melanomas described in children, and I think I am right also in saying that these are separate cases from the case in the literature of placental transmission of a malignant maternal melanoma which occurred in the foetus. The B.M.F. record was concerned only with metastasis of melanoma in the products of conception, and they had several instances of placental metastasis. There are about five, and in addition two definite cases where a mother has transmitted melanoma to the baby and in only one of these was a placenta examined seriously, and it was involved of course. In one of these cases before the child was extensively diseased it was already excreting melanin in the urine. A very remarkable phenomenon. 'This is the only tumour which does in fact pass the placental barrier, with the exception of one case of a sarcoma.

Dr. Harrison: Gray's case was a malignant tumour of the suprarenal. That baby died long after the mother-about a year-and with very very great manoeuvring they got the baby in hospital and a post-mortem was performed by Gray; every organ was sectioned, and there was no sign whatever of tumour in the baby. The placenta was full of it, but the baby was free so far as detailed histology could reveal.

PROF. AIRD: Those of you who are interested in higher diplomas should really bear in mind that this tumour is the classical melanoma you are so liable, in the stress of examination, to forget all about. Any recently-appearing, rapidly-growing, proliferating, ulcerating tumour of the back or legs should raise the strong suspicion in your minds of a melanoma, whether it is pigmented or not.

Dr. Harrison: Specially beware of the one which is not overtly pigmented.

Prof. AIRD: Close inspection of the skin round is very important. You very commonly get what looks like a proliferating ulcerating epithelioma with no signs of pigment in it, but you can see very faint patches of pigment in the neighbourhood.

DR. LENNOX: I remember a woman a couple of years ago who had a melanoma near the umbilicus. That was histologically very like this one, and con- sisted of tumour which did not appear to be attached to the overlying skin. A great majority of these tumours have no visible connection with the deeper parts of the skin. That woman died within a year with widespread metastases. I think site is very important.

DR. HARRISON : In the Leeds series an important point made was that the older the patient the worse the prognosis.

Prof. AIRD: Where do you think the primary has been in this case?

Dr. LENNOX: I do not know. Normally it is readily explicable as being proliferation of melanocytes.

Prof. AIRD: You are assuming that this is a primary tumour. I suppose it is.

DR. LenNox: I think so. The umbilical one was, I think, a primary.

Mr. Selwyn Taylor: I thought as Dr. Mason described this tumour that I detected the slightest hesitancy in the way he made his diagnosis; he was not absolutely certain. She does not show a junction of overlying epithelium and mitoses are infrequent; one might raise the suspicion of histiocytoma.

Mr. EwING: 'The clinical photograph of this case is almost precisely the same as a histiocytoma we saw last term and also the low power view of the skin. I think it is interesting that Mr. Selwyn Taylor raises that point.

Prof. AIRD: The pigment was proved to be melanin. Do you ever get melanin in a histiocytoma?

Dr. Harrison: As the person responsible for this diagnosis I will try to justify it. We bore in mind this problem of melanoma versus sclerosing angioma. Firstly we established that this did give histio-chemical reactions for melanin, and we did silver reticulin impregnations to exclude the vascular arrangement. I think we can justify our diagnosis of melanoma as far as possible We are less certain about malignancy. It fulfils all the tests we know how to apply.

Mr. Selwyn Taylor: The pathologists have convinced themselves of the diagnosis of this case.

Dr. HARRISON: Having ' bought it' once, we are now a bit cagey about diagnosis.

Mr. R. Shackman: Are the non-pigmented tumours more malignant?

DR. HARRISON: I know of no co-relation at all.

DR. LENNOX: I think it is true to say that there is none.

Mr. R. Shackman: You cannot look upon it then as an expression of differentiation?

DR. HARRISON: I mounted a specimen of liver in which roughly one-half of the metastases were black as ink and the other half quite white. 
Mitoses alone are almost valueless. I was almost biased by the details of cytology and only brought in mitoses as a secondary consideration.

DR. LENNOX: Granulation tissue proliferation has some outside stimulus. In the case of rodent ulcer the rodent ulcer cells can multiply very rapidly which, nevertheless, does not make them metastasize. If you identify cells as melanoblasts and find them proliferating elsewhere it is probably a melanoma.

Dr. HaRRISON: In this type of tumour the presence of mitosis in a particular site has certain clinical associations. That has been observed by several people over many years.

MR. EwING: Regarding the management of this case, can one make a good case for doing a gland dissection and, if so, why concentrate on the groin and not the popliteal glands? One wonders whether gland dissection is really worth while; it is an irreversible change.
DR. POWELL: In Wright's paper he co-related the clinical findings and says there is no point really in doing dissection if the glands are involved; the operation will not really lengthen the life of the patient.

Mr. EwING: Mr. Shackman can mention a case where a patient was admitted in Professor Grey Turner's time with a swelling at the angle of the mandible, which was found to be secondary to a melanoma; the significance of a pigmented mole on the lower eyelid was apparent. He had a lesion in his rib and came back about eight years later. This is the only patient with a secondary melanoma still alive after so many years, of whom I know. He died after attempted resection.

Dr. Mason: Although people will not make definite statements about melanomata in particular, the latest American book says that mitoses do not occur in benign melanomata. They make that categorical statement.

\section{MEDICAL \\ SICKNESS SOCIETY}

Insure your Income

with Sickness and Accident Insurance that is

\section{NON-CANCELLABLE and ENTITLED TO SHARE IN PROFITS}

\author{
BUYING A CAR? \\ Ask for details of \\ HIRE PURCHASE \\ through the \\ MEDICAL SICKNESS \\ FINANCE CORPORATION
}

For particulars please write to the Society

7 CAVENDISH SQUARE

LONDON

W. 1

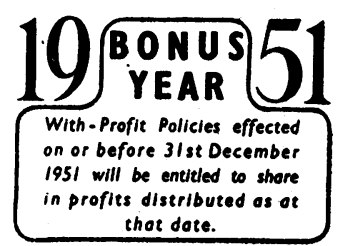

Telephone : LANghaM 2992 